\title{
Lipid profile and risk of ovarian tumours: a meta-analysis
}

\author{
Justina Ucheojor Onwuka ${ }^{1}$ (D), Akinkunmi Paul Okekunle $e^{2,3,4^{*}+}$ (D), Olaniyi Matthew Olutola ${ }^{3}$ (D), \\ Onoja Matthew $\mathrm{Akpa}^{3,5+}$ (D) and Rennan Feng ${ }^{2^{*}+}$
}

\begin{abstract}
Background: Existing data from several reports on the association between lipid profile and ovarian tumour (OT) suggests divergent conclusions. Our aim was to examine whether circulating lipid profile: total cholesterol (TC), triglyceride $(\mathrm{TG})$, high-density lipoprotein $(\mathrm{HDL})$ and low-density lipoprotein (LDL) differed between cases and noncases of OT.

Methods: Electronic repositories; PUBMED, EMBASE and Cochrane library were explored through December 2019 to retrieve published articles for inclusion in the meta-analysis after quality assessment. Heterogeneity was assessed using $P^{2}$ statistics, the effect of individual studies on the overall effect size was tested using sensitivity analysis and funnel plot was used to evaluate publication bias.

Results: Twelve studies, involving 1767 OT cases and 229,167 non-cases of OT were included in this meta-analysis and $P^{2}$ statistics ranged between 97 and 99\%. Mean circulating TC $(-16.60[-32.43,-0.77] \mathrm{mg} / \mathrm{dL} ; P=0.04)$ and $\mathrm{HDL}$ $(-0.25[-0.43,-0.08] \mathrm{mmol} / \mathrm{L} ; P=0.005)$ were significantly lower among OT cases compared to non-OT cases.

Conclusion: Decreased TC and HDL profiles were observed among subjects with OT in this collection of reports. The implications of TC and HDL in tumour manifestations and growth need to be validated in a large multi-ethnic longitudinal cohort adjusting for relevant confounders.
\end{abstract}

Keywords: Lipid profile, Total cholesterol, Triglyceride, High-density lipoprotein, Low-density lipo-protein, Ovarian tumour

\section{Introduction}

Ovarian cancer is the most deadly gynaecological malignancy among women, comprising diverse groups of neoplasm [1]. It accounts for $2.3 \%$ of all cancer-related death in the US [2], 4\% of all new cancer cases among women, the fifth commonest cancer and the fourth cause of malignancy-related death in the UK [3]. Lipids are biologically-important hydrophobic molecules vital

\footnotetext{
*Correspondence: akinokekunle@gmail.com; fengrennan@163.com

${ }^{\dagger}$ Akinkunmi Paul Okekunle, Onoja Matthew Akpa and Rennan Feng contributed equally to this work.

${ }^{2}$ Department of Nutrition and Food Hygiene, College of Public Health, Harbin Medical University, 157 Baojian Street, Harbin, Heilongjiang 150081, People's Republic of China

Full list of author information is available at the end of the article
}

for energy storage, cell signalling, maintenance of cell membrane integrity [4] and are transported in the bloodstream with the aid of lipoprotein [5].

Several studies have reported the relationship between lipid profiles; total cholesterol (TC), triglycerides (TG), high-density lipoprotein cholesterol (HDL) and lowdensity lipoprotein cholesterol (LDL) and ovarian tumour (OT) with different conclusions. For example, Camuzcuoglu et al. [6] and Bukhari et al. [7] in separate reports observed TC was significantly lower among OT patients compared to healthy controls. Contrariwise, Melvin et al. [8] observed no difference in circulating TC profiles between cases and non-cases of OT. Furthermore, Gadomska et al. [9] and Camuzcuoglu et al.

(c) The Author(s). 2020 Open Access This article is licensed under a Creative Commons Attribution 4.0 International License, which permits use, sharing, adaptation, distribution and reproduction in any medium or format, as long as you give appropriate credit to the original author(s) and the source, provide a link to the Creative Commons licence, and indicate if changes were made. The images or other third party material in this article are included in the article's Creative Commons licence, unless indicated otherwise in a credit line to the material. If material is not included in the article's Creative Commons licence and your intended use is not permitted by statutory regulation or exceeds the permitted use, you will need to obtain permission directly from the copyright holder. To view a copy of this licence, visit http://creativecommons.org/licenses/by/4.0/. The Creative Commons Public Domain Dedication waiver (http://creativecommons.org/publicdomain/zero/1.0/) applies to the data made available in this article, unless otherwise stated in a credit line to the data. 
[6] found HDL profile was lower among OT patients compared to healthy controls. Whereas, Delimaris et al. [10] and Melvin et al. [8] found no association between HDL and OT risk.

Drawing vivid inferences from prior population-based studies on lipid profile and OT risk appears difficult because of disparities in participants' selections, study designs, etc. In addition, scientific evidence on this subject is of great significance to clarify whether alterations in circulating lipid profiles are sufficient to promote OT risk or these alterations are only a reflection of previously compromised health status.

To this effect, a comprehensive analysis, comprising previous studies across diverse population would be necessary. Therefore, this study investigated the true difference in circulating lipid profiles (TC, TG, HDL and LDL) among subjects with and without OT using a meta-analytical approach.

\section{Materials and methods}

This meta-analysis was prospectively registered on PROSPERO (https://www.crd.york.ac.uk/PROSPERO/ display_record.php?ID $=$ CRD42018099728) and conducted using the MOOSE guidelines [11, 12]. Electronic scientific repositories; PubMed, EMBASE and Cochrane Library were extensively searched (without language and period of publication restrictions) through December 2019 to identify published studies using the following keywords: "lipid profile" OR "total cholesterol" OR "triglycerides" OR "high-density lipoprotein" OR "low-density lipoprotein" AND "ovarian cancer" OR "ovarian carcinoma" OR "epithelial ovarian cancer" OR " epithelial ovarian carcinoma" OR "ovarian benign tumour" OR "ovarian malignant tumour" OR "ovarian tumour". Also, references of retrieved articles were searched manually for more studies and PRISMA flowchart explaining the search methodology is shown in Fig. 1. In addition, evaluation of titles and abstracts of retrieved articles were independently done by two reviewers and difference(s) were addressed in consultation with a third reviewer.

\section{Study selection}

A study is included in the meta-analysis if it; (a) is a casecontrol studies in human population that investigated the association between lipid profiles and ovarian tumour, (b) compared cases (women with ovarian tumour) with noncases (women without ovarian tumour) and (c) reported lipid profile (TC and/or HDL and/or LDL and/or TG) in bloodstream in at least two groups (cases and non-cases) for comparison in a singular study. Similar reports among pregnant and lactating women, animals and cell lines were excluded. Also, abstracts, reviews, letter to the editor and conference papers were excluded.

\section{Quality assessment of studies}

The methodological quality and risk of bias of studies included in the meta-analysis were assessed using the Cochrane Collaboration guidelines and the NewcastleOttawa scale [13]. Briefly, two reviewers independently appraised the quality of studies and dissimilarities were conciliated by a third reviewer.

\section{Data extraction}

Name of authors, year of publication, country, study population, sample size, lipid profile(s) determined, methods of analysis, criteria for case definition, mean values [with standard deviation (SD), standard error of mean (SEM), confidence interval (CI)] of serum lipid profile (TC, HDL, LDL and TG) were extracted independently by two reviewers and differences in data extractions were resolved in recourse to a third reviewer. To ensure uniformity of estimates, mean values of TC were transformed to $(\mathrm{mg} / d L)$, but TG, HDL and LDL were transformed to $(\mathrm{mmol} / L)$. Also, all values reported as SEM and CI were transformed into SD [14].

\section{Statistical analysis}

Heterogeneity of pooled effect estimate and the magnitude of variation across studies was assessed using $I^{2}$ test statistics. A random-effects model was used to obtain mean estimates under considerable heterogeneity (i.e $I^{2}$ test $>50 \%$ or $P<0.05$ ), but a fixed-effect model was applied to obtain mean estimates when $I^{2}$-test $<50 \%$ or $P>0.05$. The random effect model postulates mean estimates of lipid profile(s) differed across studies, but follow a distribution and pooled mean is estimated as the average mean difference with an assumption that differences in mean estimates are symmetrically distributed. However, the fixed effect estimates assumed that observed differences are primarily an after-effect of chance $[12,15]$.

Statistical analysis was conducted using Review Manager 5.3 and two-tailed $P<0.05$ was considered statistically significant. Sensitivity analysis of pooled mean estimates was assessed using a leave-one-out method and publication bias was assessed using a funnel plot.

\section{Results}

\section{Literature search}

Of the 1619 records obtained from the primary literature search, 377 duplicates and 1079 records were excluded after examining titles and abstracts. Also, 151 records were excluded after full-text evaluation and 12 studies [6-10, 16-22] comprising 1767 OT cases and 229,167 non-cases of OT met the inclusion criteria (Fig. 1). Characteristics of the included studies are shown in Table 1. 


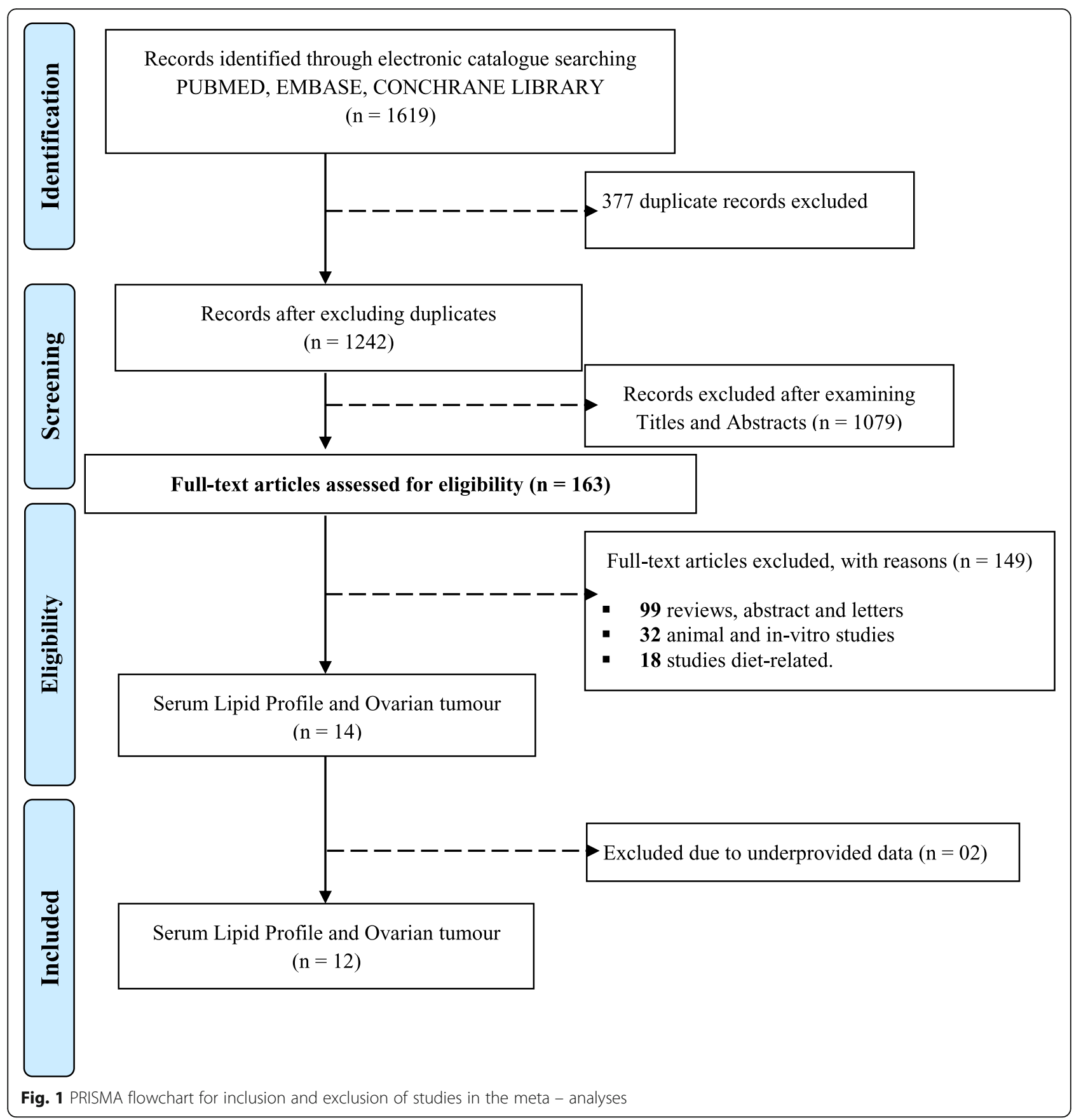

Pooled mean difference of circulating TC, TG, LDL, HDL between OT and non-OT subjects

Mean TC; - 16.60 [-32.43, - 0.77] $m g / d \mathrm{~L}, P=0.04$ was significantly lower among OT cases compared to nonOT subjects (Table 2 and Fig. 2). Similarly, mean HDL; $-0.25[-0.43,-0.08] \mathrm{mmol} / L, P=0.005$ was significantly lower among OT cases compared to non-OT subjects. However, these differences were insignificant after stratifying by age groups. Also, mean TG and LDL differed insignificantly between OT and non-OT subjects.
Stratifying our meta-analysis by age (Table 2), TG profile was significantly elevated; $0.61[0.57,0.65] \mathrm{mmol} / L \quad P<$ 0.0001 among OT subjects $<49$ years only. Contrariwise, LDL profile was significantly elevated; 0.37 [0.24, $0.50] \mathrm{mmol} / L P<0.0001$ among OT subjects $>49$ years only. TC was significantly lower $(-31.55[-62.72,-0.37] \mathrm{mg} / \mathrm{dL}$ $P<0.05$ ) among OT subjects with malignant and/or advanced tumours. TC and LDL profiles were insignificantly different, but HDL profile was significantly lower between $\mathrm{OT}$ and non-OT subjects in studies with low risk of bias. 
Table 1 Characteristics of all eligible studies for lipid profile and risk of ovarian tumours

\begin{tabular}{|c|c|c|c|c|c|c|c|c|}
\hline Authors & Year & Country & Cases & Control & $\begin{array}{l}\text { Lipid } \\
\text { profile }^{a}\end{array}$ & Ascertainment of ovarian tumour cases & Classification $^{f}$ & $\begin{array}{l}\text { Accountability } \\
\text { of bias }\end{array}$ \\
\hline $\begin{array}{l}\text { Bukhari et al. } \\
\text { [7] }\end{array}$ & 2016 & Pakistan & 30 & $30^{\mathrm{e}}$ & $\begin{array}{l}\text { TC, TG, } \\
\mathrm{HDL}, \mathrm{LDL}^{\mathrm{b}}\end{array}$ & $\begin{array}{l}\text { Hospital/Medical record confirmed using color flow } \\
\text { Doppler tests, biopsies and MRI }\end{array}$ & NR & NR \\
\hline $\begin{array}{l}\text { Camuzcuoglu } \\
\text { et al. [6] }\end{array}$ & 2009 & Turkey & 24 & $29^{e}$ & $\begin{array}{l}\text { TC, TG, } \\
\text { HDL, LDL }\end{array}$ & Hospital/Medical record & $\mathrm{FIGO}$ & Excluded $^{g, h}$ \\
\hline $\begin{array}{l}\text { Chen et al. } \\
{[16]}\end{array}$ & 2017 & China & 573 & $1146^{d}$ & $\mathrm{TG}, \mathrm{HDL}^{\mathrm{b}}$ & Hospital confirmed & $\mathrm{FIGO}$ & Excluded ${ }^{h, i}$ \\
\hline Das et al. [17] & 1987 & China & 28 & $66^{\mathrm{e}}$ & $\mathrm{TC}^{\mathrm{b}}$ & Histopathological examinations & NR & NR \\
\hline $\begin{array}{l}\text { Delimaris et al. } \\
\text { [10] }\end{array}$ & 2007 & Greece & 15 & $30^{d}$ & $\begin{array}{l}\text { TC, HDL, } \\
\text { LDL }^{\mathrm{b}}\end{array}$ & Hospital/Medical records, & TNM & Excluded $^{9}$ \\
\hline $\begin{array}{l}\text { Gadomska } \\
\text { et al. [18] }\end{array}$ & 1997 & $N R$ & 25 & $25^{\mathrm{e}}$ & $\begin{array}{l}\mathrm{TC}, \mathrm{TG}, \\
\mathrm{HDL}^{\mathrm{b}}\end{array}$ & Histopathological examinations & $\mathrm{FIGO}$ & NR \\
\hline $\begin{array}{l}\text { Gadomska } \\
\text { et al. [9] }\end{array}$ & 2005 & Poland & 91 & $44^{e}$ & $\begin{array}{l}\mathrm{TC}, \mathrm{TG}_{1} \\
\mathrm{HDL}^{\mathrm{b}}\end{array}$ & $\begin{array}{l}\text { Histopathological examinations, Transvaginal } \\
\text { ultrasonography, }\end{array}$ & $\mathrm{FIGO}$ & NR \\
\hline $\begin{array}{l}\text { Knapp et al. } \\
{[19]}\end{array}$ & 2017 & Poland & 74 & $81^{e}$ & $\mathrm{TC}, \mathrm{TG}$ & $\begin{array}{l}\text { Transvaginal sonography evaluation, Histopathological } \\
\text { examinations, CT scan }\end{array}$ & $\mathrm{FIGO}$ & Excluded ${ }^{h, i}$ \\
\hline $\begin{array}{l}\text { Kuesel et al. } \\
{[20,23]}\end{array}$ & 1992 & Canada & 62 & $51^{\mathrm{e}}$ & $\mathrm{TC}, \mathrm{TG}$ & NR & $\mathrm{FIGO}$ & NR \\
\hline Melvin et al [8] & 2012 & Sweden & 786 & $\begin{array}{l}227 \\
603^{d}\end{array}$ & $\begin{array}{l}\text { TC, TG, } \\
\text { HDL, LDL }\end{array}$ & Verifiable database & NR & NR \\
\hline $\begin{array}{l}\text { Qadir et al. } \\
\text { [21] }\end{array}$ & 2008 & Pakistan & 40 & $50^{d}$ & $\begin{array}{l}\text { TC, TG, } \\
\mathrm{HDL}, \mathrm{LDL}^{\mathrm{b}}\end{array}$ & NR & NR & Excluded $^{h}$ \\
\hline Yam et al. [22] & 1994 & Israel & 19 & $12^{c}$ & $\begin{array}{l}\mathrm{TC}, \mathrm{TG} \\
\mathrm{HDL}, \mathrm{LDL}^{\mathrm{b}}\end{array}$ & Biopsies of ovary/endometrium & NR & NR \\
\hline
\end{tabular}

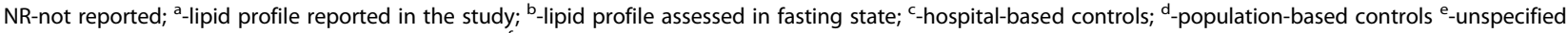
type of controls; MRI-magnetic resonance imaging; ${ }^{f}$-method adopted for tumour classification; FIGO-International Federation of Gynecologists and Obstetricians; TNM-The TNM Classification of Malignant Tumours

${ }^{9}$ Patients with previously-performed chemo-therapy, radiotherapy and surgery

hPatients with concurrent or previous malignant disease or any other disease

'Patients with suspected abnormalities such as neoplastic effects etc

Table 2 Mean difference and 95\% Cl of Lipid Profile between cases and non-cases of ovarian tumours

\begin{tabular}{|c|c|c|c|c|c|c|c|c|}
\hline & TC $(m \mathrm{~g} / d \mathrm{~L})$ & $\mathbf{D}$ & TG $(m \mathrm{~mol} / \mathrm{L})$ & D & HDL $(m \mathrm{~mol} / \mathrm{L})$ & D & LDL $(m \mathrm{~mol} / \mathrm{L})$ & $\overline{\mathbf{D}}$ \\
\hline All Studies & $-16.60[-32.43,-0.77]^{*}$ & $\downarrow$ & $0.06[-0.19,0.30]$ & $\leftrightarrow$ & $-0.25[-0.43,-0.08]^{*}$ & $\downarrow$ & $0.11[-0.24,0.47]$ & 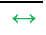 \\
\hline \multicolumn{9}{|l|}{ Age groups } \\
\hline Young adults ( $<49$ years) & $-24.34[-60.98,12.29]$ & $\leftrightarrow$ & $0.61[0.57,0.65]^{\wedge}$ & $\uparrow$ & $\neq$ & & $\ddagger$ & \\
\hline Older adults ( $>49$ years) & $-19.69[-48.25,8.88]$ & $\leftrightarrow$ & $-0.03[-0.30,0.23]$ & $\leftrightarrow$ & $-0.41[-1.19,0.37]$ & $\leftrightarrow$ & $0.37[0.24,0.50]^{\wedge}$ & $\uparrow$ \\
\hline \multicolumn{9}{|l|}{ Type of tumour } \\
\hline Benign & $-13.61[-40.26,13.04]$ & $\leftrightarrow$ & $0.01[-0.20,0.22]$ & $\leftrightarrow$ & $\ddagger$ & & $\neq$ & \\
\hline Malignant & $-37.65[-70.93,-4.37]^{*}$ & $\downarrow$ & $0.11[-0.04,0.27]$ & $\leftrightarrow$ & $-0.57[-0.68,-0.46]^{\wedge}$ & $\downarrow$ & $\neq$ & \\
\hline \multicolumn{9}{|l|}{ Stage of Cancer } \\
\hline Early $(\leq \mathrm{II})$ & $\neq$ & & $\neq$ & & $\neq$ & & $\neq$ & \\
\hline Advanced $(\geq \mathrm{III})$ & $-27.22[-87.62,33.19]$ & $\leftrightarrow$ & $-0.21[-0.67,0.24]$ & $\leftrightarrow$ & $\neq$ & & $\neq$ & \\
\hline \multicolumn{9}{|l|}{ Type and/or Stage } \\
\hline Benign \& Early & $8.52[-34.18,51.21]$ & $\leftrightarrow$ & $0.01[-0.18,0.21]$ & $\leftrightarrow$ & $-0.27[-0.36,-0.18]^{\wedge}$ & $\downarrow$ & $\neq$ & \\
\hline Malignant \& Advanced & $-31.55[-62.72,-0.37]^{*}$ & $\downarrow$ & $-0.00[-0.16,0.15]$ & $\leftrightarrow$ & $-0.28[-0.93,0.37]$ & $\leftrightarrow$ & $\neq$ & \\
\hline \multicolumn{9}{|l|}{ Risk of Bias of included Studies } \\
\hline Low & $-16.18[-52.15,19.80]$ & $\leftrightarrow$ & $0.15[-0.10,0.39]$ & $\leftrightarrow$ & $-0.25[-0.47,-0.04]^{*}$ & $\downarrow$ & $0.25[-0.15,0.66]$ & $\leftrightarrow$ \\
\hline High & $-16.50[-32.35,-0.64]^{*}$ & 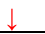 & $-0.00[-0.23,0.23]$ & $\leftrightarrow$ & $-0.25[-0.53,-0.03]^{*}$ & & $-0.22[-0.29,-0.15]^{\wedge}$ & \\
\hline
\end{tabular}

D-direction of mean difference relative to non-ovarian tumour cases; TC-Total cholesterol; TG-Triglycerides; HDL-High density lipoprotein; LDL-Low density lipoprotein

${ }^{*} p<0.05$

$\wedge p<0.00001$

₹ studies were insufficient to carry out the meta-analysis

$\uparrow$ mean difference significantly higher among cases than non-cases of ovarian tumour

$\downarrow$ mean difference significantly lower among cases than non-cases of ovarian tumour

$\leftrightarrow$ mean difference insignificantly different between cases than non-cases of ovarian tumour 


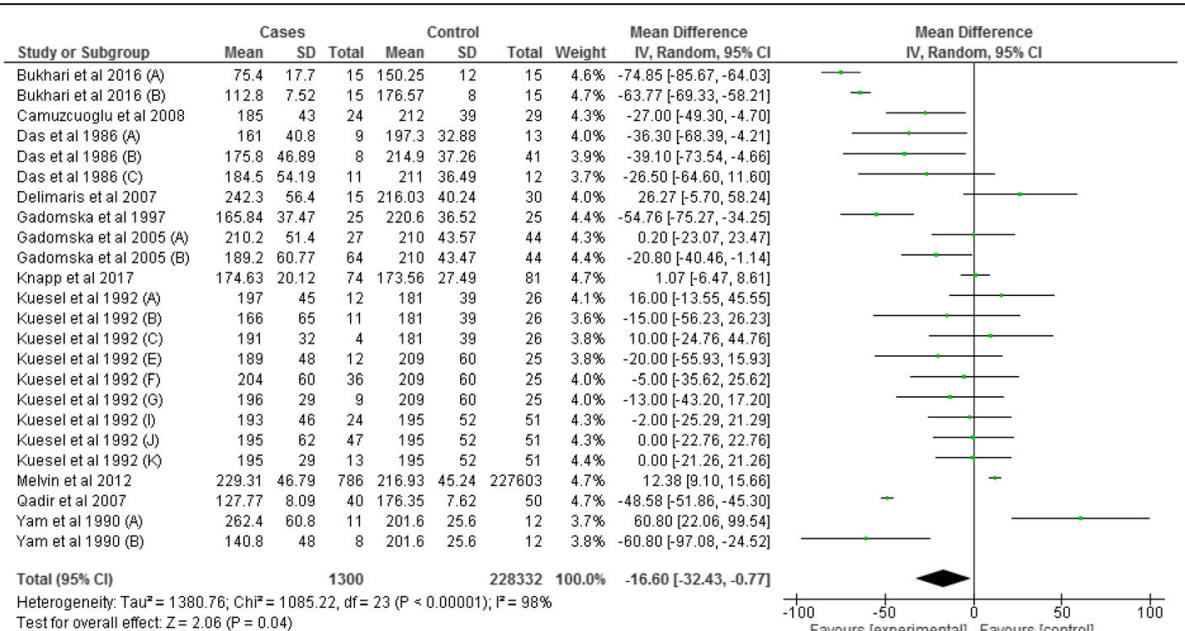

(A)

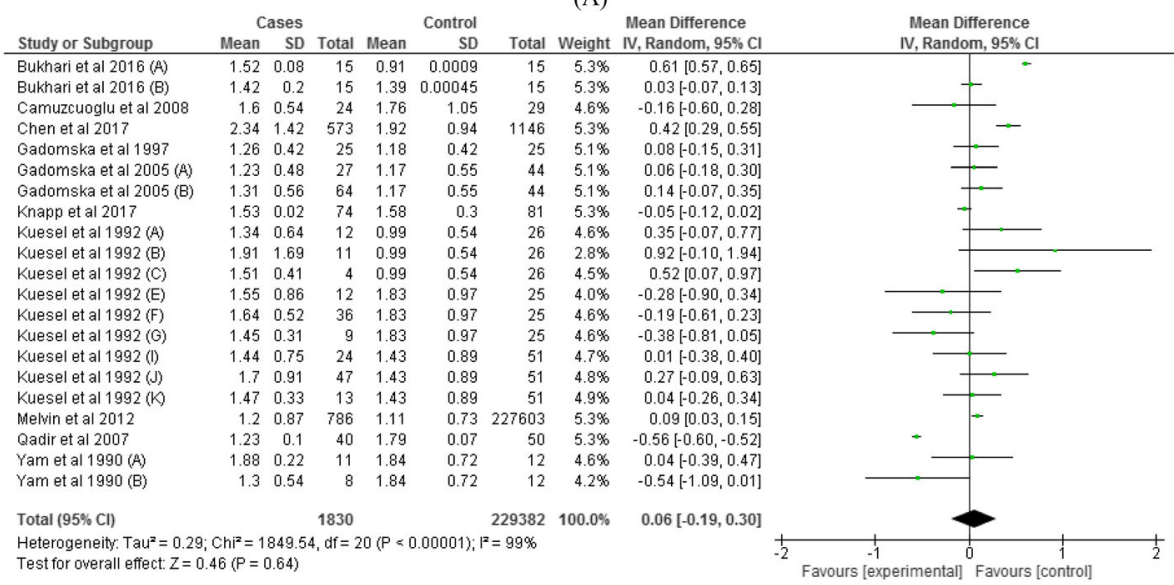

(B)

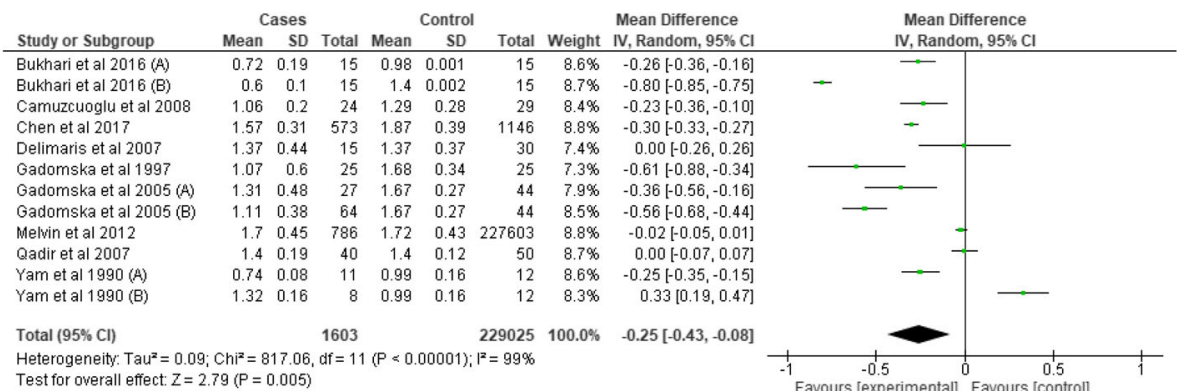

(C)

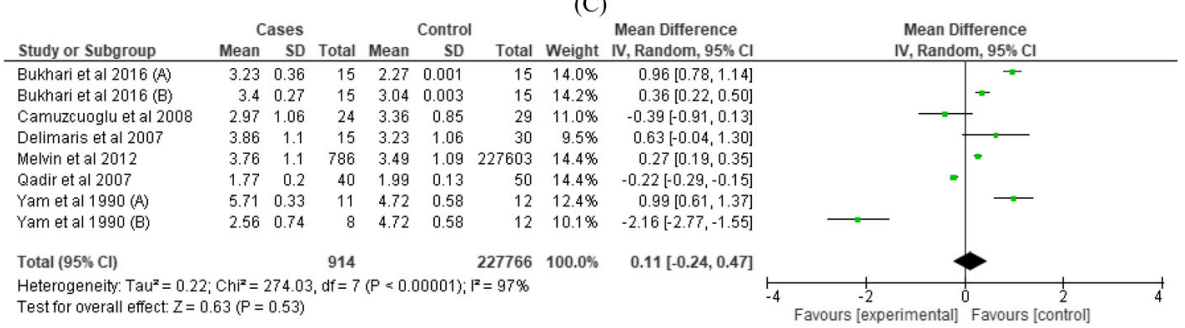

(D)

Fig. 2 Forest plot of lipid profile; total cholesterol (a), triglyceride (b), HDL (c) and LDL (d) between cases and non-cases of ovarian tumour 


\section{Quality assessment and risk of bias}

Fifty percent of studies included in the meta-analysis suggested a low risk of bias (Table S1). The bias observed in most studies was mostly attributed to incongruities in the case definition of OT (Figure S2).

\section{Publication bias}

There was no significant evidence of publication bias from the funnel plots (Figure S1) in the meta-analysis.

\section{Sensitivity analysis}

Overall pooled mean estimates differed insignificantly upon the exclusion of a single study at a time (Table S2), but few studies $[7,17,18,21,22]$ exerted negligible influence on the overall pooled mean estimates of the meta-analysis.

\section{Discussion}

To the best of our knowledge, this is the first metaanalytical study reporting true mean differences of circulating lipids and OT risk. Total cholesterol and HDL profiles were significantly lower among OT subjects, but TG and LDL profiles were insignificant in OT risk. We opined that these results highlight the significance of lipids in OT outcomes. The quality of reports included in our meta-analysis may largely influence these associations, but the findings of the stratified analysis represent a significant strength and modest evidence for significant alterations of lipid profile in OT risk is likely.

Whether altered lipid profiles are a causal or consequential factor of OT risk is debatable. However, our findings aligned with the plausibility of the latter. Circulating lipid profiles are largely subject to alterations in the occurrence of tumour events [24]. Cholesterol can be acquired from diet or endogenous biosynthesis and some studies [23, 25] have established the contributions of higher dietary cholesterol to OT risk. The occurrence of significantly lower circulating TC in OT subject may be preclinical and perhaps attributable to chronic exposure to higher cholesterol intakes. On the other hand, our findings appear consistent with other reports where TC was lower across several cancer sites [26-28]. Furthermore, the strong affinity of cancer cells for sterols and lipids makes lipid metabolism a critical factor in cancer signalling $[29,30]$. For example, excessive production of lipogenic enzymes has been observed in several cancers [31] and is linked with cancer severity and reoccurrence $[32,33]$. Also, increased signalling activity of a combination of steroid hormone receptors and growth factors via several complex metabolic circuits [34-36] modulate and activate SREBP-1 - the principal regulatory factor of lipogenesis in cancer cells.

HDL and LDL are prominent cholesterol-transporting agents vital in evaluating lipid profile in cancer signalling
[29, 30]. In our study, we observed HDL (and not LDL) was inversely related to OT risk. The conventional purpose of HDL involves the assemblage of cholesterol from peripheral tissues for transportation to the liver for the purpose of excretion [37]. In tandem with our findings, Gadomska et al. [18] in a multidimensional analysis established lower concentrations of HDL sub-fractions of total cholesterol and esterified cholesterol significantly discriminated women with ovarian neoplasm. It is plausible that HDL (more than LDL) perhaps is the focal driver of the TC-OT risk link given the absence of an association between LDL and OT risk. From a clinical point of view, the pathophysiology of the inverse HDLOT link is yet to be well understood. However, the high demand for cholesterol in cancers can as well impose the upregulation of scavenger receptor class $B$ type 1 to mobilize HDL for increased cholesterol influx to promote proliferation and hormone synthesis for tumour cell growth and survival thereby leading to decrease in circulating HDL [38]. On this premise, it is not strange that the applicability and viability of lipoprotein-based nanoparticles drug delivery mechanism for cancer treatment have been reported in the literature [39-41]. For example, the biocompatibility, reliability and viability of engineered HDL nanoparticles conjugated with folic acid as carriers drug delivery targets to metastatic ovarian cancer sites in mouse models has been documented [39].

In addition, there is evidence of a modest inverse association between TC or HDL and breast cancer risk [28]. The anti-inflammatory properties of HDL in inhibiting cell proliferation and apoptosis [42] in addition to plummeting LDL oxidative potency in order to prevent increased intracellular oxidative stress is a critical step in cancer pathogenesis [43]. Decreased HDL levels are associated with increased levels of pro-inflammatory cytokines, including tumour necrosis factor-alpha and interleukin-6 [44].

Also, LDL differed insignificantly between OT and nonOT subjects in this current meta-analysis. This finding has been well reported in studies $[28,45]$ from other cancer sites. Tumour cells express increased LDL receptor levels which lead to low LDL levels [46]. LDL receptors are regulated by the SREBP transcriptional assembly [47] and can promote the intracellular influx of cholesterol to induce carcinogenesis. Conversely, excess cholesterol and its oxidized metabolites can activate liver $\mathrm{X}$ receptors and retinoid $\mathrm{X}$ receptors heterodimeric transcriptional factors to suppress LDL and induce ABC-family transporter expression to promote cholesterol efflux [48].

Our study has both strengths and limitations. Our report is the first meta-analysis highlighting the significance of lipid profile and risk of ovarian neoplasm. The higher statistical power arising from a large number of participants in 
our report potentially offer credibility to our findings. In addition, our funnel plots could not rule out the potential for publication bias in this meta-analysis. However, most studies included in our meta-analysis were cross-sectional (owing to limited cohort reports) and limited studies agematched cases with controls in the eligible studies. The number of studies on this subject is comparatively rare, making the clarification of our findings quite challenging. Our findings must be interpreted with caution given a temporal sequence of causal association cannot be inferred and perhaps prone to reverse causality. In spite of the biological plausibility of the association between lipid profile and OT risk, there are many confounders involved in OT carcinogenesis. Overweight/obesity and its associated comorbidities significantly promote OT risk among women [49]. Similarly, excessive weight gain is associated with features of metabolic syndrome and low circulating HDL levels [50]. Information regarding these confounders and comorbidities such as; diabetes, endometriosis, OT subtypes, weight status, smoking status, use of hormone replacement therapy or statin and/or fibrate treatment, etc. were relatively omitted in most reports included in our meta-analysis. Hence, prospective cohort studies adjusting for these confounders are recommended to validate the findings of this meta-analysis. Also, the bias of recall, selection and confounding is likely, but the quality assessment of studies and indifference in the overall our findings after a sensitivity analysis justifies the legitimacy of our results.

\section{Conclusion}

Our meta-analysis presents evidence of a modest significant association between circulating HDL and risk of OT. It is vital to elucidate the implications of HDL in tumour manifestations and growth. There is a need to validate these findings using large multi-ethnic longitudinal cohorts effectively adjusting for age, menopausal status, preclinical prejudice and other key confounding factors.

\section{Supplementary information}

Supplementary information accompanies this paper at https://doi.org/10. 1186/s12885-020-6679-9.

Additional file 1. Supplementary Table S1: Critical assessment of included studies using the Newcastle-Ottawa Scale (NOS). Supplementary Figure S1: Funnel plot of lipid profile; total cholesterol (A), triglyceride (B), HDL (c) and LDL (D) between cases and non-cases of ovarian tumours; summarizing the publication bias in the meta-analysis. Supplementary Figure S2: Graphical illustration of the results of the critical assessment of studies; Is the Case Definition Adequate? (S1), representativeness of the Cases (S2), selection of Controls (S3), definition of Controls (S4), comparability of cases and controls on the basis of the design or analysis (C1), ascertainment of exposure (E1), same method of ascertainment of exposure for cases and controls (E2), overall risk of bias of all studies included. Supplementary Table S2: Sensitivity Analysis (using one study leave out method) of pooled mean differences of Lipid profiles between cases and non-cases of ovarian tumour.

Additional file 2. A Meta-analysis Of Observational Studies in Epidemiology (MOOSE) Checklist.

\section{Abbreviations}

Cl: Confidence interval; HDL: High-density lipoprotein; LDL: Low-density lipoprotein; OT: Ovarian tumour; SD: Standard deviation; SEM: Standard error of the mean; TC: Total cholesterol; TG: Triglyceride

\section{Acknowledgements}

Not applicable.

\section{Authors' contributions}

JUO, APO, OMA and RNF: prepared the study design; JUO, APO and OMO: conducted the literature search, data acquisition and analysis; OMA and RNF provided guidance and technical assistance in data acquisition and analysis; JUO and APO: drafted the manuscript; APO, RNF and OMA: revised the manuscript. All authors read and approved the final version to be published.

\section{Funding}

This study was supported by the National Natural Science Foundation of China (81872616). The China Scholarship Council supported JUO (2017BSZ011594) and APO (2015BSZ778). Also, APO received partial funding from the Postgraduate College, University of Ibadan.

\section{Availability of data and materials}

The dataset(s) supporting the conclusions of this article is(are) included within the article (and its additional file(s))

\section{Ethics approval and consent to participate}

Not applicable. The protocol of our meta-analysis was prospectively registered on PROSPERO (https://www.crd.york.ac.uk/PROSPERO/display_record. php?|D=CRD42018099728).

\section{Consent for publication}

Not applicable.

\section{Competing interests}

The authors declare that they have no competing interests.

\section{Author details}

${ }^{1}$ Department of Epidemiology, College of Public Health, Harbin Medical University, 157 Baojian Street, Harbin, Heilongjiang Province 150081, People's Republic of China. ${ }^{2}$ Department of Nutrition and Food Hygiene, College of Public Health, Harbin Medical University, 157 Baojian Street, Harbin, Heilongjiang 150081, People's Republic of China. ${ }^{3}$ Department of Epidemiology and Medical Statistics, College of Medicine, University of Ibadan, Ibadan 200284, Nigeria. ${ }^{4}$ The Postgraduate College, University of Ibadan, Ibadan 200284, Nigeria. ${ }^{5}$ Institute of Cardiovascular Diseases, College of Medicine, University of Ibadan, Ibadan 200284, Nigeria.

Received: 25 October 2019 Accepted: 24 February 2020

Published online: 12 March 2020

References

1. McCluggage WG. Morphological subtypes of ovarian carcinoma: a review with emphasis on new developments and pathogenesis. Pathology. 2011; 43(5):420-32..

2. Noone AM, H.N., Krapcho M, Miller D, Brest A, Yu M, Ruhl J, Tatalovich Z, Mariotto A, Lewis DR, Chen HS, Feuer EJ, Cronin KA (eds). SEER Cancer Statistics Review (CSR) 1975-2015. 2018 September 10, 2018 [cited 201813 September 2018]; April 2018:[Available from: https://seer.cancer.gov/csr/1 975_2015/ based on November 2017 SEER data submission, posted to the SEER web site.

3. Cancer Research UK. Ovarian cancer statistics; 2018. https://www. cancerresearchuk.org/health-professional/cancer-statistics/statistics-bycancer-type/ovarian-cancer\#heading-Zero. Accessed 2018.

4. Melvin JC, et al. Serum lipid profiles and cancer risk in the context of obesity: four meta-analyses. J Cancer Epidemiol. 2013;2013:823849. 
5. Uccello M, et al. Lipoprotein(a) as a potential marker of residual liver function in hepatocellular carcinoma. Indian J Med Paediatr Oncol. 2011. 32(2):71-5.

6. Camuzcuoglu $\mathrm{H}$, et al. Serum paraoxonase and arylesterase activities in patients with epithelial ovarian cancer. Gynecol Oncol. 2009;112(3):481-5.

7. Bukhari SA, et al. Oxidative stress-induced DNA damage and homocysteine accumulation may beinvolved in ovarian cancer progression in both young and old patients. Turk J Med Sci. 2016;46(3):583-9.

8. Melvin JC, et al. Lipid profiles and risk of breast and ovarian cancer in the Swedish AMORIS study. Cancer Epidemiol Biomark Prev. 2012;21(8):1381-4.

9. Gadomska $H$, et al. Serum lipids concentration in women with benign and malignant ovarian tumours. Eur J Obstet Gynecol Reprod Biol. 2005;120(1): 87-90.

10. Delimaris I, et al. Oxidized LDL, serum oxidizability and serum lipid levels in patients with breast or ovarian cancer. Clin Biochem. 2007:40(15):1129-34.

11. Stroup DF, et al. Meta-analysis of observational studies in epidemiology: a proposal for reporting. Meta-analysis of observational studies in epidemiology (MOOSE) group. JAMA. 2000;283(15):2008-12.

12. Higgins, J.P.T. and S. Green, eds. Cochrane Handbook for Systematic Reviews of Interventions. Vol. Version 5.1.0 [updated March 2011]. 2011, The Cochrane Collaboration. Available from www.cochrane-handbook.org. Accessed 01 Nov 2018

13. Wells, G.A., et al. The Newcastle-Ottawa Scale (NOS) for assessing the quality of nonrandomised studies in meta-analyses. 20142014 [cited 2016 May]; Available from: http://www.ohri.ca/programs/clinical_epidemiology/oxford. asp.

14. Hozo SP, Djulbegovic B, Hozo I. Estimating the mean and variance from the median, range, and the size of a sample. BMC Med Res Methodol. 2005;5:13.

15. Higgins JP. Commentary: heterogeneity in meta-analysis should be expected and appropriately quantified. Int J Epidemiol. 2008;37(5):1158-60.

16. Chen $Y$, et al. Case-control study of metabolic syndrome and ovarian cancer in Chinese population. Nutr Metab. 2017;14(1):21.

17. Das NP, Ma CW, Salmon YM. The relationship of serum vitamin a, cholesterol, and triglycerides to the incidence of ovarian cancer. Biochem Med Metab Biol. 1987;37(2):213-9.

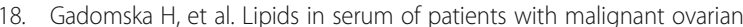
neoplasms. Int J Gynaecol Obstet. 1997;57(3):287-93.

19. Knapp $P$, et al. Plasma and ovarian tissue sphingolipids profiling in patients with advanced ovarian cancer. Gynecol Oncol. 2017;147(1):139-44.

20. Kuesel AC, et al. Lipoprotein(a) and CA125 levels in the plasma of patients with benign and malignant ovarian disease. Int J Cancer. 1992;52(3):341-6.

21. Qadir MI, Malik SA. Plasma lipid profile in gynecologic cancers. Eur J Gynaecol Oncol. 2008;29(2):158-61.

22. Yam D, et al. Insulin and glucose status, tissue and plasma lipids in patients with tumours of the ovary or endometrium: possible dietary implications. Br J Cancer. 1994;70(6):1186-7.

23. Kuesel AC, Kroft T, Préfontaine M, Smith IC. Lipoprotein(A) And Ca125 Levels In The Plasma Of Patients With Benign And Malignant Ovarian Disease. Int I Cancer. 1992;52(3):341-6.

24. Law MR, Thompson SG. Low serum cholesterol and the risk of cancer: an analysis of the published prospective studies. Cancer Causes Control. 1991; 2(4):253-61.

25. Knekt $P$, Steineck G, Järvinen R, Hakulinen T, Aromaa A. Intake of fried meat and risk of cancer: a follow-up study in Finland. Int J Cancer. 1994;59(6):756-60.

26. Iso H, Ikeda A, Inoue M, Sato S, Tsugane S, JPHC Study Group. Serum cholesterol levels in relation to the incidence of cancer: the JPHC study cohorts. Int J Cancer. 2009;125(11):2679-86.

27. Patel PS, Shah MH, Jha FP, Raval GN, Rawal RM, Patel MM, Patel JB, Patel DD. Alterations in plasma lipid profile patterns in head and neck cancer and oral precancerous conditions. Indian J Cancer. 2004;41(1):25-31.

28. Touvier $\mathrm{M}$, et al. Cholesterol and breast cancer risk: a systematic review and meta-analysis of prospective studies. Br J Nutr. 2015;114(3):347-57.

29. Gorin A, Gabitova L, Astsaturov I. Regulation of cholesterol biosynthesis and cancer signaling. Curr Opin Pharmacol. 2012;12(6):710-6.

30. Cruz PM, Mo H, McConathy WJ, Sabnis N, Lacko AG. The role of cholesterol metabolism and cholesterol transport in carcinogenesis: a review of scientific findings, relevant to future cancer therapeutics. Front Pharmacol. 2013:4:119. https://doi.org/10.3389/fphar.2013.00119. Published 2013 Sep 25.

31. Nagahashi $M$, et al. Sphingosine-1-phosphate produced by sphingosine kinase 1 promotes breast cancer progression by stimulating angiogenesis and lymphangiogenesis. Cancer Res. 2012;72(3):726-35.
32. Mashima T, Seimiya H, Tsuruo T. De novo fatty-acid synthesis and related pathways as molecular targets for cancer therapy. Br J Cancer. 2009;100(9): 1369-72.

33. Uddin S, et al. High prevalence of fatty acid synthase expression in colorectal cancers in middle eastern patients and its potential role as a therapeutic target. Am J Gastroenterol. 2009;104(7):1790-801.

34. Bhatia B, et al. Mitogenic sonic hedgehog signaling drives E2F1-dependent lipogenesis in progenitor cells and medulloblastoma. Oncogene. 2011;30(4): 410-22.

35. Menendez JA, Lupu R. Fatty acid synthase and the lipogenic phenotype in cancer pathogenesis. Nat Rev Cancer. 2007;7(10):763-77.

36. Oliveras $\mathrm{G}$, et al. Novel anti-fatty acid synthase compounds with anti-cancer activity in HER2+ breast cancer. Ann N Y Acad Sci. 2010;1210:86-92.

37. Marz W, et al. HDL cholesterol: reappraisal of its clinical relevance. Clin Res Cardiol. 2017;106(9):663-75.

38. Morin EE, Li XA, Schwendeman A. HDL in Endocrine Carcinomas: Biomarker, Drug Carrier, and Potential Therapeutic. Front Endocrinol (Lausanne). 2018;9: 715. https://doi.org/10.3389/fendo.2018.00715. Published 2018 Nov 30.

39. Corbin $I R$, et al. Near-infrared fluorescent imaging of metastatic ovarian cancer using folate receptor-targeted high-density lipoprotein nanocarriers. Nanomedicine (London, England). 2013;8(6):875-90.

40. Shahzad MM, et al. Targeted delivery of small interfering RNA using reconstituted high-density lipoprotein nanoparticles. Neoplasia. 2011;13(4): 309-19.

41. Murakami T, et al. Intracellular drug delivery by genetically engineered highdensity lipoprotein nanoparticles. Nanomedicine (Lond). 2010;5(6):867-79.

42. Kim S, Keku TO, Martin C, Galanko J, Woosley JT, Schroeder JC, Satia JA, Halabi S, Sandler RS. Circulating levels of inflammatory cytokines and risk of colorectal adenomas. Cancer Res. 2008;68(1):323-8.

43. Zuo T, Zhu M, Xu W. Roles of oxidative stress in polycystic ovary syndrome and cancers. Oxidative Med Cell Longev. 2016;2016:8589318.

44. Haddy N. IL-6, TNF- $a$ and atherosclerosis risk indicators in a healthy family population: the STANISLAS cohort. Atherosclerosis. 2003;170(2):277-83.

45. Siemianowicz K, Gminski J, Stajszczyk M, Wojakowski W, Goss M, Machalsk M, Telega A, Brulinski K, Magiera-Molendowska H. Serum total cholesterol and triglycerides levels in patients with lung cancer. Int J Mol Med. 2000; 5(2):201-5.

46. Raju K, Punnayanapalya SS, Mariyappa N, Eshwarappa SM, Anjaneya C, Kai LJ. Significance of the Plasma Lipid Profile in Cases of Carcinoma of Cervix: A Tertiary Hospital Based Study. Asian Pac J Cancer Prev. 2014;15(8):377984.

47. Radhakrishnan A, et al. Switch-like control of SREBP-2 transport triggered by small changes in ER cholesterol: a delicate balance. Cell Metab. 2008;8(6): $512-21$

48. Zelcer $\mathrm{N}$, et al. LXR regulates cholesterol uptake through Idol-dependent ubiquitination of the LDL receptor. Science. 2009:325(5936):100-4.

49. Crosbie EJ, et al. Body mass index, hormone replacement therapy, and endometrial cancer risk: a meta-analysis. Cancer Epidemiol Biomark Prev. 2010;19(12):3119-30.

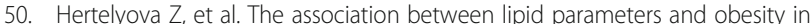
university students. J Endocrinol Investig. 2016;39(7):769-78.

\section{Publisher's Note}

Springer Nature remains neutral with regard to jurisdictional claims in published maps and institutional affiliations.

Ready to submit your research? Choose BMC and benefit from:

- fast, convenient online submission

- thorough peer review by experienced researchers in your field

- rapid publication on acceptance

- support for research data, including large and complex data types

- gold Open Access which fosters wider collaboration and increased citations

- maximum visibility for your research: over $100 \mathrm{M}$ website views per year

At $\mathrm{BMC}$, research is always in progress.

Learn more biomedcentral.com/submissions 